\title{
A Retrospective Analysis: Development and Validation of a Nomogram Model for Predicating 30- day Mortality in ST-Segment Elevation Myocardial Infarction Patients
}

Bin Wang ( $13575915795 @ 163 . c o m$ )

Dongyang People's Hospital https://orcid.org/0000-0002-4709-0600

MaoFeng Wang

Dongyang People's Hospital

ManZhen Ying

Dongyang People's Hospital

Chengjiang Liu

Anhui Medical University

Research article

Keywords: ST-Segment Elevation Myocardial Infarction,STEMI,nomogram

Posted Date: February 21st, 2020

DOI: https://doi.org/10.21203/rs.2.24201/v1

License: (a) (i) This work is licensed under a Creative Commons Attribution 4.0 International License.

Read Full License 


\section{Abstract}

Objective: To develop and validate a personalized nomogram model to predict 30-day mortality in patients with ST-Segment Elevation Myocardial Infarction (STEMI).

Methods: A total of 1144 STEMI patients admitted to Dongyang People's Hospital from June 2013 to October 2019 were enrolled in the study and divided into two groups: Model group $(n=801)$ and validation group ( $n=343$ ). The biomarkers (maximum) in 24 hours after admission and the basic information of the patients were taken as variables, including creatinine, pro B-type natriuretic peptide (proBNP) and troponin T, as well as age, gender, etc. Logistic stepwise regression was employed to screen out independent risk factors that may led to death in patients with acute STEMI. A nomogram predication model was established with the screened independent risk factors as variables. Area underReceiver Operating Characteristic (ROC) curve and GiViTI calibration chart were adopted to estimate the classification accuracy and calibrate the predication model, respectively, and decline curve analysis (DCA) to assess the clinical efficiency of the model.

Results: Logistic stepwise regression revealed that proBNP, creatine kinase-MB (CK-MB), age, creatinine, lactic acid and percutaneous coronary intervention (PCI) surgery or not were independent risk factors that decided whether a STEMI patient would die. After the establishment of the model, area under ROC curve was 0.897 and 0.859 in model group and validation group, respectively, suggesting that the new model was a good classifier. $P$ value of GiViTI calibration test was 0.834 and 0.262 , respectively. $P>0.05$ in GiViTI calibration indicated a high goodness of fit between the predication ratio of the model and the actual ratio, showing that the calibration of predications models in model group and validation group was complete. DCA curves in model group and validation group were both above two extreme curves, which suggested a good clinical significance.

Conclusion: The personalized model for predicating 30-day mortality in patients with STEMI will help screen out those STEMI patients who may die in a short term.

\section{Introduction}

Ischemic heart disease is the leading cause of death worldwide, with an increasing incidence [1]. In Europe, ischemic heart disease results in almost 1.8 million deaths every year, accounting for $20 \%$ of all deaths [2]. ST-Segment Elevation Myocardial Infarction (STEMI) is one major disease in patients with ischemic heart disease. Sweden may be the country with the most comprehensive STEMI recording information in Europe [3,4]. The morbidity of STEMI in Sweden was 58/100,000 in 2015 while that in other European countries ranged from 43-144/100,000 every year [5]. The mortality, however, is still at a high level. According to statistics of ESC countries, the in-hospital mortality in STEMI patients is between $4-12 \%$. For this reason, when faced with acute myocardial infarction, the first-line clinicians are usually under much pressure due to the dangerous and severe disease condition, uncertainty in prognosis, etc. Besides, the top concern for a patient' family members is whether the patient will die. The Thrombolysis 
in Myocardial Infarction (TIMI) and Global Registry of Acute Cardiac Events (GRACE) risk scores are tools to measure prognosis of myocardial infarction in clinical practices, but GRACE is more suitable for cases with non-ST segment elevation acute coronary syndromes (NSTE ACS). Although TIMI risk score can be used to assess the short-term prognosis of STEMI patients, it is only available for patients who underwent thrombolysis and anticoagulant therapy ${ }^{[9,10]}$. Currently, there is no available clinical methods to predicate whether STEMI patients (including those who did not receive thrombolysis therapy) will die in a short term. Therefore, it is necessary to develop a method to predicate whether STEMI patients will progress to death in a short term. This study aims to develop a reliable and accurate risk predication model, thus providing evidence and clues for early identification and screening of those STEMI patients who have a high mortality risk in a short term.

\section{Materials And Methods}

\section{Patient enrollment}

A retrospective analysis was carried out on 1144 patients with acute STEMI 1827 patients remained after excluding those complicated with acute chronic obstructive pulmonary disease (COPD), pulmonary thromboembolism (PTE), aortic dissection, pneumothorax, noncardiac shock, chronic renal failure, or hepatic failure from a total of 1839 patients and 1144 cases were finally included in the study after further excluding those with missing data) admitted in Dongyang People's Hospital (a 3B hospital) from June 2013 to October 2019. Inclusion criteria: 1. patients who suffered from chest distress or pain and then were definitely diagnosed with STEMI based on electrocardiogram, 2. Those who were complicated with PTE, COPD, aortic dissection, pneumothorax, shock or pulmonary infection were excluded, 3 . Those with missing data were excluded. Among them, there were 100 deaths. All objects were randomly divided into two groups in line with R statistical software: Model group ( $n=80,173$ deaths) and validation group ( $n=34,327$ deaths). Patients who did not undergo thrombolysis or $\mathrm{PCl}$ were given platelet aggregation and lipid-lowering therapy to stabilize plaques in accordance with standard treatment procedures of myocardial infarction.

\section{Moral statement}

The research was approved by the ethics committee of Dongyang People's Hospital. All patients or their family members were informed of the research contents and signed the informed consent. All the data was analyzed anonymously and personal identifying information was deleted completely. This research was performed in accordance with principles in Declaration of Helsinki and its revisions. 


\section{Selection of risk factors}

General data (gender, age, diabetes, hypertension), PCl or not, thrombolysis or not, troponin $\mathrm{T}(\mathrm{ng} / \mathrm{mL})$, creatinine $(\mu \mathrm{mol} / \mathrm{L})$, pro B-type natriuretic peptide (proBNP) $(\mathrm{pg} / \mathrm{mL})$, creatine kinase-MB $(C K-M B)(U / L)$, aspartate aminotransferase (AST) $(\mathrm{U} / \mathrm{L}$ ) and lactic acid $(\mathrm{mmol} / \mathrm{L})$ (The maximum values of these indexes in 24 hours after admission were taken as the objective data in blood tests) were collected and analyzed.

\section{Statistical description}

The enrolled patients were randomly divided model group and validation group using $\mathrm{R}$ software, with death as the classification standard (Troponin T above 10 and proBNP above 35,000 were treated as equal to 10 and 35,000 in EXCEL). First, the basic materials of two cohorts were compared: The categorical variables were presented as frequency (\%) and tested by chi-square test. The continuous variables, which were in abnormal distribution and had a sample size below 5000 , took median (quartile) and analyzed by rank sum test.The continuous variables were verified to see whether they were available for logistic regression and were in linear relation with logit $(p)$. They were tested using BoxTidwell functions.In addition, all variables were tested with multicollinearity and variance inflation factors (VIF) were used for interpretation. Univariate and logistic stepwise regression were adopted and $p=0.05$ was taken as the testing standard for screening variables (Two models were developed using $\mathrm{R}$ software with 7 variables including troponin $\mathrm{T}$ in the multivariate logistic regression before stepwise regression. The statistical analysis revealed that there was no statistical significance between the two models, so stepwise regression was adopted for modeling). After that, 6 variables were included in the model, with which a personalized nomogram for predicating short-term death in STEMI patients was established in model group: ${ }^{[11,12]}$ The predication model was assessed from the discrimination, calibration and clinical effects. The discrimination of a predication model means whether it can effectively predicate the survival or death in a patient with acute STEMI. The results can be evaluated by calculating the area under the ROC curve ${ }^{[10]}$. A model is meaningful when AUC value lies between 0.5 to 1 . The closer AUC for the model comes to 1 , the better it is. In general, a model with AUC of $0.5-0.75$ is considered to be meaningful while AUC $>0.75$ means it has excellent measure of separability ${ }^{[13]}$. The calibration of the predication model means the consistency between the predication probability and observation density. A calibration chart was developed for judgment and it showed that the overlapping-degree of the logistic fitting curve and standard curve was high, suggesting a good predicating effect. $P>0.05$ indicated a good goodnessof-fit ${ }^{[14]}$.In the present study, DCA curve (Figure IV) was used for assessing and interpreting clinical efficiency of the model: $Y$-axis is the clinical benefit of the model, $X$-axis is the risk value of disease and 
model curve is the curve of the model. With All curve and None (two extreme curves) as standards, it was considered that the farther model curve was from two extreme curve, the better the clinical significance would be and it would generate clinical net benefits ${ }^{[15,16]}$. All the above procedures were completed in $\mathrm{R}$ software.

\section{Results}

1. Basic information of patients: In the present study, a total of 1,144 patients were enrolled and divided into model group $(n=801)$ and validation group $(n=343)$. The detailed information was shown in the chart(As shown in the Tablel)

2. Results about whether continuous variables were in linear relation with logit $(p)$ : Based on $p$ values, all continuous variables were in linear relation with logit $(p)(p>0.1$ was considered as statistically significant) and could be employed to perform logistic regression. (As shown in the Tablell)

3. All variables were tested with multicollinearity and variance inflation factors (VIF) were used for interpretation: A VIF above 10 indicates multicollinearity and the closer it comes to 1, the less connected the variables are. (As shown in the TablellI)

4. Analysis results of univariate and logistic regression are shown in the Figure:(As shown in the TableIV).Logistic stepwise regression revealed that age, proBNP, creatinine, CKMB, LAC and PCI had $p$ values $<0.05$, with statistical significance, so they were used for modeling.

5. Establishment of nomogram

Six independent risk factors were included in the predication model based on multivariate logistic stepwise regression. Then a personalized nomogram predication model was established (Figurel). Interpretation of the nomogram: The score of each predication index was acquired based on the nomogram and the sum of all scores was taken as the total points. For example: A 60-year old patient with acute STEMI who did not receive PCI surgery and whose proBNP was 15,000 pg/mL, CK-MB 300 $\mathrm{U} / \mathrm{L}$, LAC $4 \mathrm{mmol} / \mathrm{L}$ and $C R 110 \mu \mathrm{mol} / \mathrm{L}$ will get a total score of 113 points, which corresponds to a death risk of $15 \%$.

\section{Evaluation of the model:}

The area under ROC curve of the model cohort was 0.897 , suggesting a good discrimination and the point of tangency was 0.132 , which means that the death risk was above 0.132 in this patient in this model. It was considered to be a high risk in this paper. (Figurell) 
Evaluation of predication accuracy: The calibration chart showed that the overlapping-degree of the logistic fitting curve and standard curve was high and $p=0.834$ suggesting a good goodness-of-fit. (Figure III)

Evaluation of clinical efficiency: DCA curve (Figure IV) was employed to evaluate the clinical efficiency. The model cohort was in the risk range of $10-90 \%$ and the curve was above the two extreme curves, without any intersection, suggest a good clinical efficiency of the model.

7. Validation of the model:

the validation of the model was also based on discrimination, calibration and clinical significance. ROC curve, calibration chart and DCA curve were drawn for validation group. The area under ROC curve of the model cohort was 0.897 (Figurell), suggesting a good discrimination and while the $p$ value of the validation cohort in calibration chart was 0.262 , indicating a good goodness-of-fit of the model in this cohort(FigurellI). DCA curve was in the the risk range of $10-80 \%$ in validation group(FigurelV). All these suggested that it was valuable in clinical practices.

\section{Discussion}

STEMI is a critical part of acute myocardial infarction, a common clinical critical disease.Some recent studies underline that the wide application of reperfusion therapy, primary percutaneous coronary intervention $(\mathrm{PCl})$, modern antithrombotic therapy and secondary prevention has brought down acute and long-term mortality of STEMI ${ }^{[2,6,7]}$, but it still acounts for about $20 \%$ of the deaths due to acute myocardial infarction ${ }^{[17,18]}$. STEMI is very worthy of investigation in view of the adverse social and economic effects caused by it.

Many factors may lead to death of STEMI patients, such as age, delayed treatment, history of myocardial infarction. Besides the above indexes, biomarkers have been used as potential clinical tools to predicate the risk of patients with acute myocardial infarction, which have provided a large amount of information to predicate prognosis ${ }^{[19]}$. Biomarkers like proBNP and hs-CRP ${ }^{[20,21]}$ have been proven to be correlated with prognosis of patients with myocardial infarction. During the screening of patients, testing results of biomarkers may often embody relevant factors that may affect prognosis. For example, a higher CK-MB index in a certain time range may indicate a delayed treatment or more cell deaths in the cardiac myocyte. The history of myocardial infarction may suggest a poor cardiac function of the patient in normal times, which will be reflected as a high proBNP ${ }^{222,23]}$. Therefore, biomarkers, which can reflect patients' state objectively, are valuable in the present study and they can also avoid bias caused by subjective factors.

In the present study a personalized nomogram for predicating 30-day death in STEMI patients was developed and its discrimination, predication accuracy and clinical efficiency were evaluated via ROC 
curve, calibration chart and DCA curve, which all suggested a good significance, indicating that this model could be a good reference in clinical practices.

In comparison to TIMI, which only evaluates short-term mortality of STEMI patients ${ }^{[9,10]}$, the model is not only available for STEMI patients who undergo thrombolysis, but also quantize the age of patients. The research has revealed the influence of different age groups on STEMI and eliminate the effects of subjective factors in killip classification. More research indexes have been included in the study, which can evaluate the prognosis of patients in a more comprehensive and objective way. The total score of a STEMI patient can be calculated with this model, which will enable clinicians to have a clear understanding about the death risk of the patient, communicate with family members in a better way and perform more effective clinical intervention on the one with high risk, thus lowering mortality.

There are still some deficiencies in the present study. (1) As a retrospective analysis, selection bias may occur inevitably. This research, however, has strictly limited the inclusion criteria and collected enough samples, of which, samples with missing data were removed to avoid bias caused by data interpolation, so it embodied the results calculated with actual clinical data. (2) All the data of the predication model is from one single center. Although randomization was adopted for grouping in the present study to perform internal validation, there is no external validation with data from other centers. (3) CRP indexes were not included in the research due to limitations in missing clinical data. Therefore, a more complete plan for acquiring indexes shall be designed in the following research. A project shall be designed in which blood samples will be collected from STEMI patients at admission, in 10-14 hours and in 20-24 hours after admission in the following 3-4 years. HS-CRP will be included besides the biomarkers in the present study and more deaths shall be collected to achieve a more accurate statistical analysis. Furthermore, external validation shall be conducted by persuading other medical centers to join in this research.

\section{Conclusion}

The personalized model for predicating 30-day mortality in patients with STEMI will help screen out those STEMI patients who may die in a short term.

\section{Abbreviations}

\section{STEMI}

ST-Segment Elevation Myocardial Infarction.

proBNP

pro B-type natriuretic peptide.

ROC

Receiver Operating Characteristic.

COPD

chronic obstructive pulmonary disease.

DCA 
decline curve analysis.

VIF

variance inflation factors.

TIMI

Thrombolysis in Myocardial Infarction.

ACS

acute coronary syndromes.

AST

aspartate aminotransferase.

GRACE

Acute Cardiac Events.

\section{Declarations}

Ethics approval and consent to participateConsent for publication

The Dongyang People's Hospitalethics committee that approved the study.

- Consent for publication

- Availability of supporting data $\triangle A$ vailability of data and materials

- Competing interests $₫ T$ There is No Competing interests.

- Funding $₫ T$ There is No Funding source.

- Authors' contributions $₫$ Bin Wang. andMaoFeng Wang. collected the data, J.W. analysedthe data,Chengjiang Liu. revised the statistical analyses, Bin Wang. wrote the paper,Chengjiang Liu. andManZhen Ying revised the paper.

- Acknowledgements $₫$ Thanks for LE JIUsystemsupport,data collection depends on LE JIU system.Tangks for data provided by Dongyang people's Hospital

Conflict of interest :The authors declare no conflict of interest.

Ethical Approval and Consent to participate

- Consent for publication

- Availability of supporting data

- Competing interests 


\section{References}

1. Hartley A, Marshall DC, Salciccioli JD, Sikkel MB, Maruthappu M, Shalhoub J. Trends in mortality from ischemic heart disease and cerebrovascular disease in Europe: 1980 to 2009. Circulation 2016;133(20):1916-1926.

2.Townsend N, Wilson L, Bhatnagar P, Wickramasinghe K, Rayner M, Nichols M. Cardiovascular disease in Europe: epidemiological update 2016. Eur Heart J 2016;37(42):3232-3245.

3.Sugiyama T, Hasegawa K, Kobayashi Y, Takahashi O, Fukui T, Tsugawa Y. Differential time trends of outcomes and costs of care for acute myocardial infarction hospitalizations by ST elevation and type of intervention in the United States, 2001-2011. J Am Heart Assoc 2015;4(3):e001445.

4.McManus DD, Gore J, Yarzebski J, Spencer F, Lessard D, Goldberg RJ. Recent trends in the incidence, treatment, and outcomes of patients with STEMI and NSTEMI. Am J Med 2011;124(1):40-47.

5.Widimsky P, Wijns W, Fajadet J, de Belder M, Knot J, Aaberge L, Andrikopoulos G, Baz JA, Betriu A, Claeys M, Danchin N, Djambazov S, Erne P, Hartikainen J, Huber K, Kala P, Klinceva M, Kristensen SD, Ludman P, Ferre JM, Merkely B, Milicic D, Morais J, Noc M, Opolski G, Ostojic M, Radovanovic D, De Servi S, Stenestrand U, Studencan M, Tubaro M, Vasiljevic Z, Weidinger F, Witkowski A, Zeymer U, European Association for Percutaneous Cardiovascular Interventions. Reperfusion therapy for ST elevation acute myocardial infarction in Europe: description of the current situation in 30 countries. Eur Heart J 2010;31(8):943-957.

6.Puymirat E, Simon T, Steg PG, Schiele F, Gueret P, Blanchard D, Khalife K, Goldstein P, Cattan S, Vaur L, Cambou JP, Ferrieres J, Danchin N, USIK USIC 2000 Investigators, FAST MI Investigators. Association of changes in clinical characteristics and management with improvement in survival among patients with ST-elevation myocardial infarction. JAMA 2012;308(10):998-1006.

7.Gale CP, Allan V, Cattle BA, Hall AS, West RM, Timmis A, Gray HH, Deanfield J, Fox KA, Feltbower R. Trends in hospital treatments, including revascularisation, following acute myocardial infarction, 2003-2010: a multilevel and relative survival analysis for the National Institute for Cardiovascular Outcomes Research (NICOR). Heart 2014;100(7):582-589.

8.Kristensen SD, Laut KG, Fajadet J, Kaifoszova Z, Kala P, Di Mario C, Wijns W, Clemmensen P, Agladze V, Antoniades L, Alhabib KF, De Boer MJ, Claeys MJ, Deleanu D, Dudek D, Erglis A, Gilard M, Goktekin O, Guagliumi G, Gudnason T, Hansen KW, Huber K, James S, Janota T, Jennings S, Kajander O, Kanakakis J, Karamfiloff KK, Kedev S, Kornowski R, Ludman PF, Merkely B, Milicic D, Najafov R, Nicolini FA, Noc M, Ostojic M, Pereira H, Radovanovic D, Sabate M, Sobhy M, Sokolov M, Studencan M, Terzic I, Wahler S, Widimsky P, European Association for Percutaneous Cardiovascular Interventions. Reperfusion therapy for ST elevation acute myocardial infarction 2010/2011: current status in 37 ESC countries. Eur Heart J 2014;35(29):1957-1970.

9.Antman EM, Cohen M, Bernink PJ, et al. The TIMI risk score for unstable angina/non-ST elevation MI: A method for prognostication and therapeutic decision making. JAMA. 2000. 284(7): 835-42.

10. Morrow DA, Antman EM, Charlesworth A, et al. TIMI risk score for ST-elevation myocardial infarction: A convenient, bedside, clinical score for risk assessment at presentation: An intravenous nPA for treatment of infarcting myocardium early II trial substudy. Circulation. 2000. 102(17): 2031-7

11. Harrell FE Jr, Califf RM, Pryor DB, Lee KL, Rosati RA. Evaluating the yield of medical tests. JAMA.1982 May 14; 247(18):2543-6. PMID: 7069920

12.Iasonos A, Schrag D, Raj GV, Panageas KS. How to build and interpret a nomogram for cancer prognosis.JClinOncol. 2008 Mar 10; 26(8):1364-70.

13. Silva TB, Oliveira CZ, Faria EF, Mauad EC, Syrja“nen KJ, Carvalho AL. Development and validation of anomogram to estimate the risk of prostate cancer in Brazil. Anticancer Res. 2015 May; 35(5):2881-6.

14.Niu XK, He WF, Zhang Y, Das SK, Li J, Xiong Y, et al. Developing a new PI-RADS v2-based nomogramfor forecasting high-grade prostate cancer ClinRadiol. 2017 Jun; 72(6):458-464 
15.Nattino G, Finazzi S, Bertolini G. A new test and graphical tool to assess the goodness of fit of logisticregression models. Stat Med. 2016 Feb 28; 35(5):709-20

16.Vickers,A.J. and E.B.Elkin,Decision curve analysis:a novel method for evaluating prediction models. MedDecis Making,2006.26(6):p.565-74.

17.Fitzgerald,M.,B.R.Saville and R.J.Lewis,Decision curve analysis.JAMA,2015.313(4):p.409-10

18. Rosamond W, Flegal K, Friday G, et al. Heart disease and stroke statistics--2007 update: a report from the American Heart Association Statistics Committee and Stroke Statistics Subcommittee. Circulation. 2007. 115(5): e69-171.

19. Lindahl B, Toss H, Siegbahn A, Venge P, Wallentin L; for the FRISC Study Group .Fragmin during instability in coronary artery disease. Markers of myocardial damage and inflammation in relation to long-term mortality in unstable coronary artery disease. N Engl J Med. 2000; 343:1139-1147.

20. James SK, Lindahl B, Siegbahn A, Stridsberg M, Venge P, Armstrong P, Barnathan ES, Califf R, Topol EJ, Simoons ML, Wallentin L. N-terminal pro-brain natriuretic peptide and other risk markers for the separate prediction of mortality and subsequent myocardial infarction in patients with unstable coronary artery disease: a Global Utilization of Strategies To Open occluded arteries (GUSTO)-IV substudy. Circulation. 2003; 108:275-281.

21.Sabatine MS, Morrow DA, de Lemos JA, Gibson CM, Murphy SA, Rifai N, McCabe C, Antman EM, Cannon CP, Braunwald E. Multimarker approach to risk stratification in non-ST elevation acute coronary syndromes: simultaneous assessment of troponin I, C-reactive protein, and B-type natriuretic peptide. Circulation. 2002; 105:1760-1763.

22.Tello-Montoliu A, Marin F, Roldan V, Mainar L, Lopez MT, Sogorb F, Vicente V, Lip GY. A multimarker risk stratification approach to non-ST elevation acute coronary syndrome: implications of troponin T, CRP, NT pro-BNP and fibrin D-dimer levels. J Intern Med. 2007; 262:651-658.

23.Cao,Jia, Zhu. BNP and NT-proBNP as Diagnostic Biomarkers for Cardiac Dysfunction in Both Clinical and Forensic Medicine[J]. International Journal of Molecular Sciences, 2019, 20(8).

\section{Tables}




\begin{tabular}{|c|c|c|c|c|c|c|}
\hline & DEV & VAD & $\mathrm{w} / \mathrm{X} 2$ & Pvalue & & \\
\hline \multirow[t]{2}{*}{ Sex } & Male $₫ 560 \square 70.0 \% \square$ & Male $₫ 233 \square 68.0 \% \square$ & 0.35552 & 0.5510 & & \\
\hline & Female $₫ 241 \square 30.0 \% \square$ & Female $₫ 110 \square 32.0 \% \square$ & & & & \\
\hline \multirow[t]{2}{*}{ PCI } & 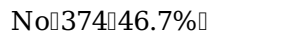 & $\mathrm{No} \square 151 \square 44.0 \% \square$ & 0.58535 & 0.4442 & & \\
\hline & Yes $\square 427 \square 53.3 \% \square$ & Yes $\square 192 \square 56.0 \% \square$ & & & & \\
\hline \multirow[t]{2}{*}{ Hyp } & $\mathrm{No} \square 308 \square 38.5 \% \square$ & $\mathrm{No} 120 \square 35.0 \% \square$ & 1.0889 & 0.2967 & & \\
\hline & Yes $\square 493 \square 61.5 \% \square$ & Yes $\llbracket 233 \square 65 \% \square$ & & & & \\
\hline \multirow[t]{2}{*}{ Dia } & Noロ610ロ76.2\%ם & $\mathrm{No} \square 248 \square 72.3 \% \square$ & 1.0003 & 0.1923 & & \\
\hline & Yes $\square 191 \square 23.8 \% \square$ & Yes $\square 95 \square 27.7 \% \square$ & & & & \\
\hline \multirow[t]{2}{*}{ Thy } & Noロ776ロ96.9\%ロ & $\mathrm{No} \square 330 \square 96.2 \% \square$ & 0.15879 & 0.6903 & \multicolumn{2}{|c|}{ Basic information of patients $\square$} \\
\hline & Yes $\square 25 \square 3.1 \% \square$ & Yes $\square 13 \square 3.8 \% \square$ & & & \multicolumn{2}{|l|}{ Table 1} \\
\hline \multirow[t]{2}{*}{ Age } & $60-81$ & $62-81$ & 135625 & 0.7326 & Variable & $\mathrm{P}$ value \\
\hline & Mean $\square 72$ & Mean $\square 72$ & & & & \\
\hline \multirow[t]{2}{*}{ Tropinin } & $0.379-4.720$ & $0.462-5.275$ & 131043 & 0.2165 & age & 0.9925 \\
\hline & Mean $\llbracket 1.818$ & Mean $\square 2.110$ & & & troponin & 0.7866 \\
\hline \multirow[t]{2}{*}{ Pro-bnp } & $490.4-5853$ & $392.5-5805$ & 140539 & 0.5763 & & \\
\hline & Mean $\llbracket 1778$ & Mean $\square 1575$ & & & & \\
\hline \multirow[t]{2}{*}{$\mathrm{Cr}$} & $70-98$ & $68-98$ & 137250 & 0.9811 & $\mathrm{cr}$ & 0.3221 \\
\hline & Mean $\square 83$ & Mean $\square 83$ & & & ckmb & 0.6014 \\
\hline \multirow[t]{2}{*}{ Ckmb } & $28-89$ & $27.5-94$ & 131088 & 0.2197 & & \\
\hline & Mean $\square 66$ & Mean $\square 59$ & & & lac & 0.6583 \\
\hline \multirow[t]{2}{*}{ Lac } & $1.4-2.9$ & $1.4-3.15$ & 130632 & 0.1878 & ast & 0.7159 \\
\hline & Mean $\llbracket 1.9$ & Mean $\square 2$ & & & & \\
\hline \multirow[t]{2}{*}{ Ast } & $40-273$ & $40-283$ & 132274 & 0.3195 & & \\
\hline & Mean $\square 106$ & Mean $\square 112$ & & & $\begin{array}{l}\text { Table } 2 \text { Rest } \\
\text { relation with }\end{array}$ & $\begin{array}{l}\text { lts about whether continuous variables were in linear } \\
\text { logit }(p)\end{array}$ \\
\hline
\end{tabular}




\begin{tabular}{|c|c|c|c|c|c|c|}
\hline Variable & Vif & & & & & \\
\hline probnp & 1.570283 & & & & & \\
\hline $\mathrm{cr}$ & 1.429362 & & & & & \\
\hline age & 1.295453 & & & & & \\
\hline ckmb & 1.214773 & & & & & \\
\hline pci & 1.205226 & & & & & \\
\hline lac & 1.199669 & & & & & \\
\hline $\operatorname{sex}$ & 1.159492 & Table 3 VIF of va & lables $\square$ & & & \\
\hline ast & 1.153015 & & & & & \\
\hline hypertension & 1.103883 & & & & & \\
\hline troponin & 1.090189 & & & & & \\
\hline diabetes & 1.062807 & & & & & \\
\hline \multirow{14}{*}{ thrombolysis } & \multirow{2}{*}{1.027963} & & \multicolumn{2}{|l|}{ Univariate analysis } & \multicolumn{2}{|l|}{ Multivariate analysis } \\
\hline & & & Or $\square 97.5 \% \mathrm{CI} \square$ & Pvalue & Or $\square 97.5 \%$ CI & Pvalue \\
\hline & & Age & $1.047660-1.107082$ & $2.18 * 10-7$ & 1.029383-1.101278 & 0.000388 \\
\hline & & Troponin & $0.979424-1.064240$ & 0.209 & NA & NA \\
\hline & & Pro.bnp & $1.000085-1.000132$ & $2.0 * 10-16$ & $1.000041-1.000102$ & $4.81 * 10-6$ \\
\hline & & Thrombolysis & $0.384449-4.962829$ & 0.432 & NA & NA \\
\hline & & $\mathrm{Cr}$ & $1.005532-1.010685$ & $9.49 * 10-10$ & $1.001291-1.006915$ & 0.003142 \\
\hline & & Diabetes & $0.140231-1.828305$ & 0.947 & NA & NA \\
\hline & & Ckmb & $1.001379-1.003525$ & $6.35 * 10-6$ & $1.002229-1.005383$ & $2.38 * 10-6$ \\
\hline & & Sex(female) & $1.196167-3.433292$ & 0.00803 & NA & NA \\
\hline & & Lac & $1.377817-1.731043$ & $9.66 * 10-14$ & $1.100171-1.429743$ & 0.000715 \\
\hline & & Hypertension & $0.781491-2.374385$ & 0.298 & NA & NA \\
\hline & & Pci.yes & $0.149912-0.488986$ & $1.88 * 10-5$ & $0.213874-0.958216$ & 0.043158 \\
\hline & & Ast & $1.000534-1.001889$ & 0.000434 & NA & NA \\
\hline
\end{tabular}

Table 4 Analysis results of univariate and logistic regression]

\section{Figures}




\section{Nomogram diagram:}

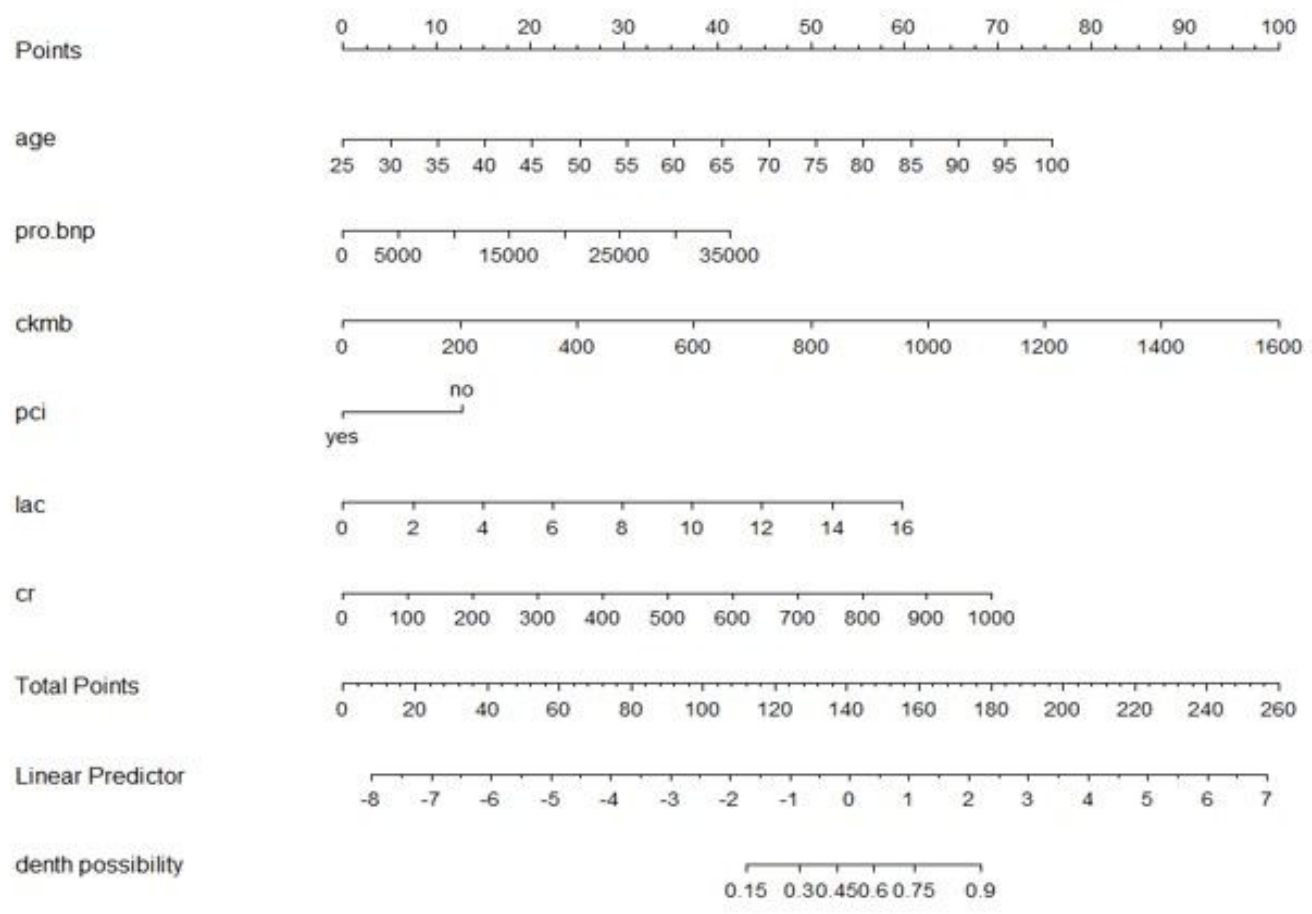

Figure 2

Six independent risk factors were included in the predication model based on multivariate logistic stepwise regression. Then a personalized nomogram predication model was established 


\section{Remarks :}

The front is ROC curve of modeling crowd, and then there's ROC curve of validation population.
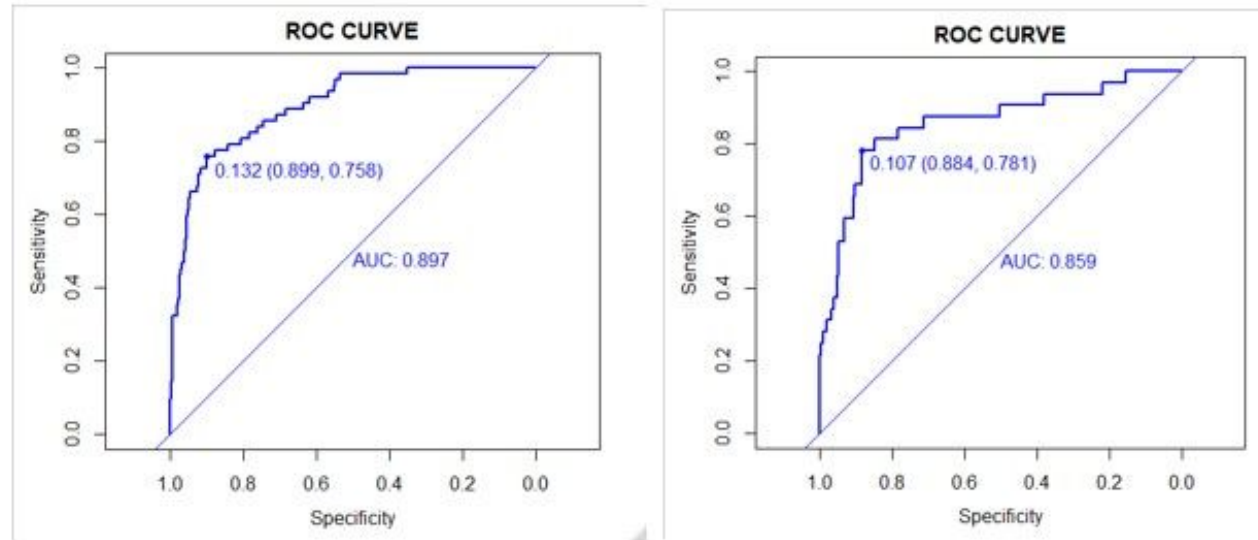

Figure 4

The area under ROC curve of the model cohort was 0.897 , suggesting a good discrimination and the point of tangency was 0.132 , which means that the death risk was above 0.132 in this patient in this model. It was considered to be a high risk in this paper

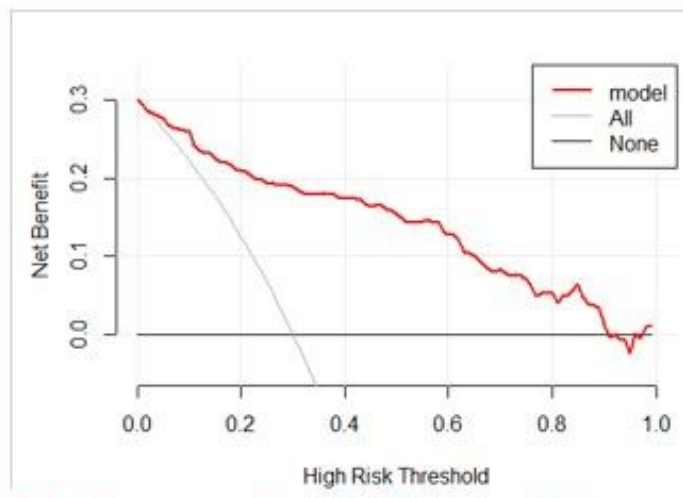

DCA curve of modeling population

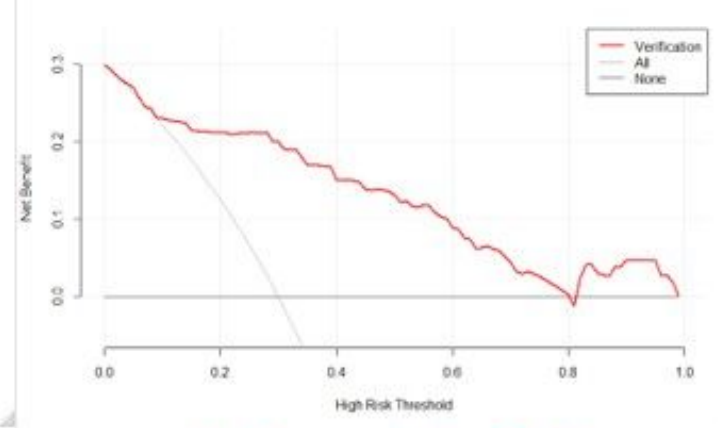

Verify population DCA curve 
Figure 6

Evaluation of predication accuracy: The calibration chart showed that the overlapping-degree of the logistic fitting curve and standard curve was high and $p=0.834$ suggesting a good goodness-of-fit.

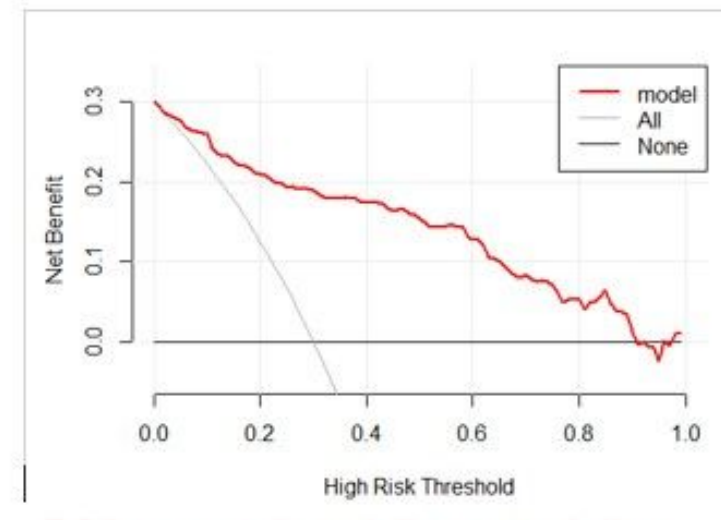

DCA curve of modeling population

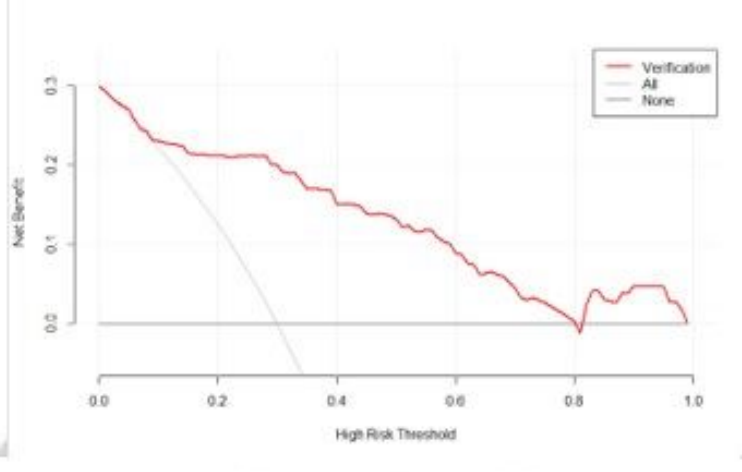

Verify population DCA curve

\section{Figure 8}

Evaluation of clinical efficiency: DCA curve 